\title{
Soil-Frost Depth Change in Eastern Hokkaido under +2 K-World Climate Scenarios
}

\author{
Masaru Inatsu ${ }^{1}$, Junpei Tominaga ${ }^{2}$, Yuta Katsuyama ${ }^{2}$ and Tomoyoshi Hirota ${ }^{3}$ \\ ${ }^{1}$ Faculty of Science, Hokkaido University, Sapporo, Japan \\ ${ }^{2}$ Graduate School of Science, Hokkaido University, Sapporo, Japan \\ ${ }^{3}$ Hokkaido Agricultural Research Center, National Agriculture and Food Research Organization, Sapporo, Japan
}

\begin{abstract}
A future change in the soil-frost depth in eastern Hokkaido was assessed with multiple local climate scenarios. The biascorrected downscaled data with an aid of a simple snow-depth model were applied to the empirical estimation from cumulative freezing degree-days (CFD) for days when the snow depth is less than $20 \mathrm{~cm}$. Consequently, as the response to global warming climate that was defined as $+2-\mathrm{K}$ world in this paper, the maximum soil-frost depth significantly decreased in the coastal regions along the Pacific and in central Tokachi subprefecture with a slight variation among climate scenarios. Parameter-sweep experiments for two observed cases clarified that the temperature increase would bring the soil warming in the environment where the insulation effect of snow cover does not work at present, while it would bring the soil frosting in the environment where the insulation effect works.
\end{abstract}

(Citation: Inatsu, M., J. Tominaga, Y. Katsuyama, and T. Hirota, 2016: Soil-frost depth change in eastern Hokkaido under +2 K-world climate scenarios. SOLA, 12, 153-158, doi:10.2151/ sola.2016-032.)

\section{Introduction}

Soil frost in response to global warming deserves to be considered for climate change adaptation of natural vegetation and agricultural crops in the high latitudes (e.g. Imai et al. 2013; Shimoda et al. 2015; Reinsdorf and Koch 2013). A series of reports of Intergovernmental Panal for Climate Change (IPCC) have emphasised a temperature increase in the cold regions more rapidly than the global-mean due to ice-albedo feedback (IPCC 2007; 2013). The snow melting would be promoted there consequently. However, the global warming does not always lead to soil-frost thawing, because soil temperatures are controlled by not only sensible heat flux at the surface but snow covering (Zhang et al. 2005; Brown and DeGaetano 2011; Iwata et al. 2010). This insulation effect of snow was discussed in terms of soil-air temperature difference, of which the annual mean was typically $1 \mathrm{~K}$ in a temperate zone (Jacobs et al. 2011) but ranged 2 to $4 \mathrm{~K}$ in a subarctic zone (Grundstein et al. 2005; Yazaki et al. 2013b). Moreover, although IPCC reports suggested a moderate increase in precipitation generally in the high latitudes under a warmer climate (IPCC 2007; IPCC 2013), the precipitation change would vary horizontally with model uncertainty in regional phenomena such as storm-tracks, atmospheric blocking, stationary eddies, and sea surface temperatures. The estimation of soil frost in response to global warming thus demands multiple local climate scenarios with sufficiently high resolution.

A set of local climate scenarios for the soil-frost estimation have mostly been elaborated with statistical downscaling with a bias correction for multiple general circulation models (GCMs) by multiple emission scenarios. For example, Sinha and Cherkauser (2010) estimated soil temperatures in the midwestern United States with the bias-corrected data (Maurer et al. 2007; Wood

Corresponding author: Masaru Inatsu, Rigaku-8th bldg., Hokkaido University, N10W8, Sapporo 060-0810 Japan. E-mail: inaz@mail.sci.hokudai. ac.jp. (C2016, the Meteorological Society of Japan. et al. 2004) under two GCMs by three emission scenarios, and Campbell et al. (2010) similarly estimated it in eastern United States. These studies obtained the decrease tendency in soil-frost. Recent publications as above have commonly discussed the soil frosting with a combination of multiple GCMs and multiple emission scenarios. However, because of a considerable discrepancy in the global-mean temperature increase among GCMs due to climate sensitivity, an ad-hoc set of local climate scenarios made from selected GCMs and emission scenarios would unintentionally exaggerate the uncertainty in temperature increase. A consideration on several periods in the future would also accentuate the uncertainty. Thinking of a complex response of soil frost to air temperature and snowfall, therefore, we have to scrupulously create a set of local climate scenarios such that the local uncertainty in snowfall is fairly incorporated and the global uncertainty in temperature is not over-emphasised.

Recently Inatsu et al. (2015) proposed +2 K-world climate scenarios with the multi-GCM dynamical downscaling (DDS) for the decade when the global warming surface air temperature (SAT) increases by $2 \mathrm{~K}$. This method successfully separated the local uncertainty from the global SAT uncertainty due to GCM's climate sensitivity and greenhouse gas emission in the future. The DDS data were provided for the target area of Hokkaido, where the snowfall is relatively heavier than other cold regions. For this local climate character, the soil frost was supposed to be much more affected by the snow depth. Hirota et al. (2006) revealed a tendency of the decrease in soil-frost depth based on long-term observation at a site in Tokachi subprefecture (Fig. 1), probably because the snowfall has recently increased in early winter by extratropical cyclone passages. Whether or not this tendency is

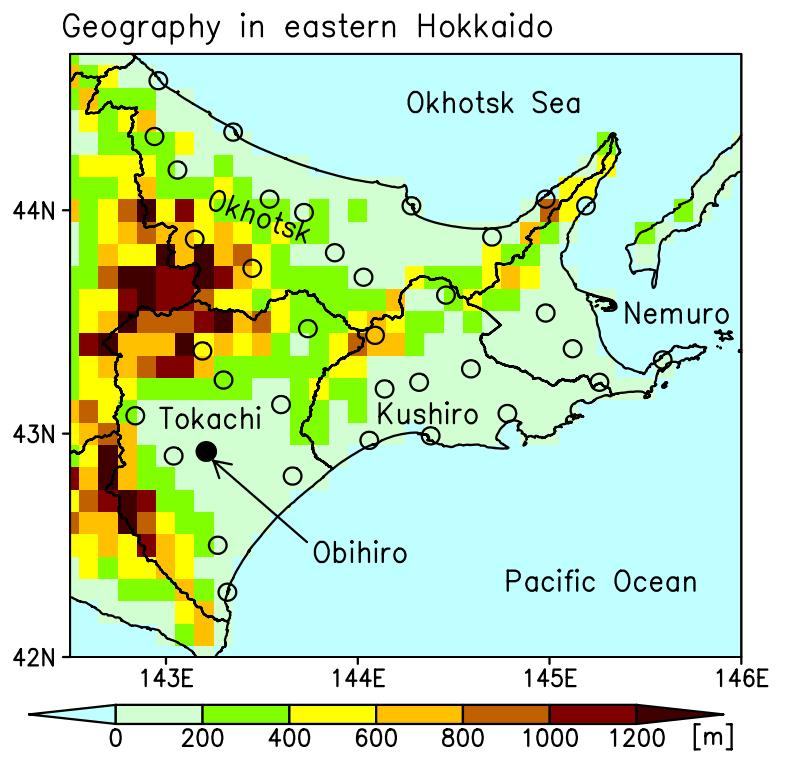

Fig. 1. The surface height from the sea level in the regional atmospheric model that was used for dynamical downscaling (DDS). The colour reference is in the bottom (m). The Automated Meteorological Data Acquisition System (AMeDAS) sites that we used are indicated by a circle mark in Tokachi, Kushiro, Nemuro, and Okhotsk subprefuctures. The AMeDAS site at Obihiro is specially marked by a filled circle. 
caused by global warming is still uncertain but it is worthwhile to examine the soil-frost in snowy regions as eastern Hokkaido. This study hence aims to evaluate a possible change in soil-frost depth in eastern Hokkaido based on DDS data with multiple GCMs imposed as the lateral boundary of the limited area model.

\section{Data}

The observed data that we used in the bias correction and snow-depth model simulation are the daily Automated Meteorological Data Acquisition System (AMeDAS) of the Japan Meteorological Agency in Tokachi, Kushiro, Nemuro, and Okhotsk subprefectures from 1991/1992 to 1999/2000 winters. Temperature, precipitation, and snow depth have been operationally observed at the AMeDAS sites shown in Fig. 1. The Japanese Reanalysis named JRA-55 (Kobayashi et al. 2015) was also utilised.

\section{Methods}

\subsection{Multiple climate scenarios}

The DDS data targeted over Hokkaido were provided with a set of regional atmospheric model integrations with three Climate Model Inter-comparison Project 3's GCMs: MIROC (Hasumi and Emori 2004), MPI (Roeckner et al. 2003), and NCAR models (Collins et al. 2006). This paper hereafter refers to them as MIROC-, MPI-, and NCAR-boundary climate scenarios, respectively. These GCM well reproduced the Northern Hemisphere winter climate among the CMIP3 simulations (Kuno and Inatsu 2014). The present-climate scenarios were based on DDS with 1990 s of each GCM and the $+2-K$ world scenarios were based on DDS with 2050s of MIROC, 2060s of MPI's model, and 2080s of NCAR's model under the Special Report on Emissions Scenario A1b (IPCC 2007). The decades in the $2-\mathrm{K}$ world scenarios were selected as the timing when the global-mean SATs increased

(a) Increase in surface air temperatures in DJF
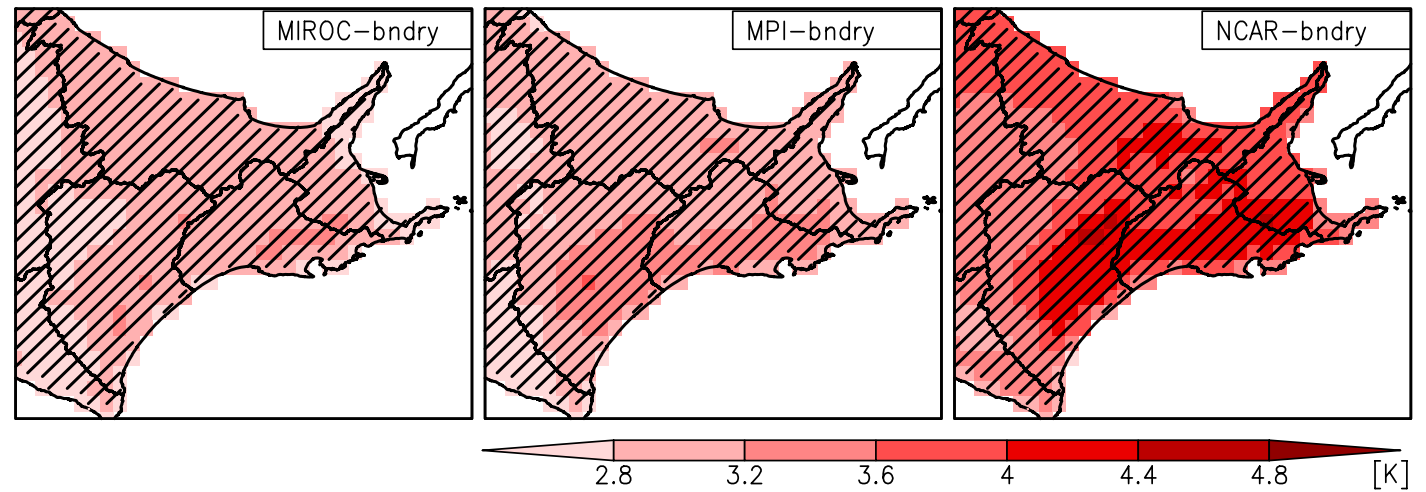

(b) Increase rate in precipitation in DJF
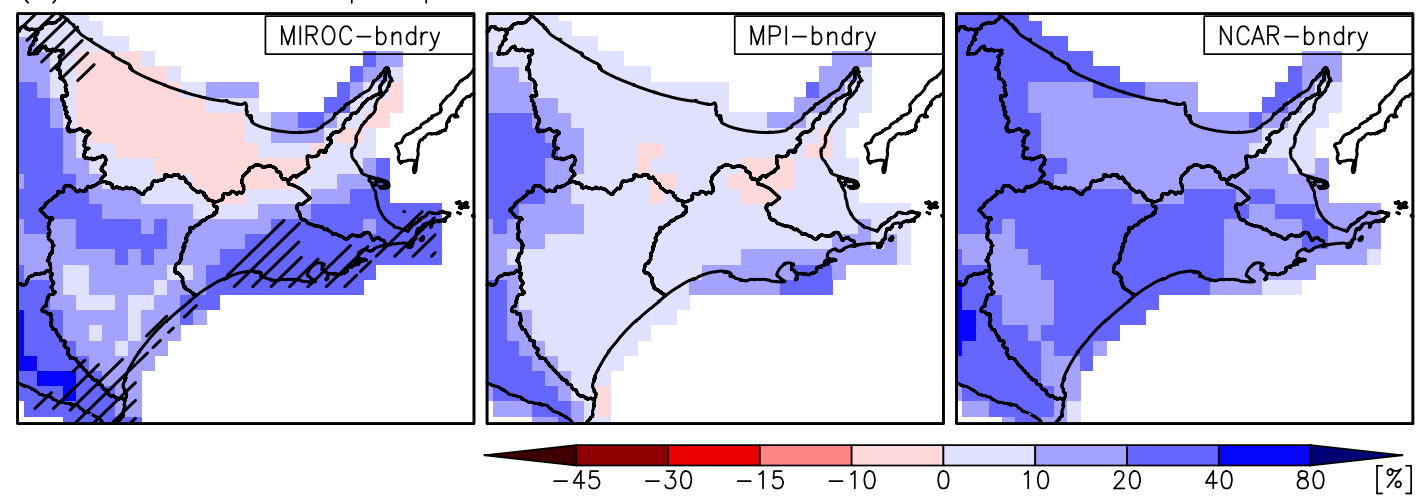

(c) Increase rate in snow depth in DJF
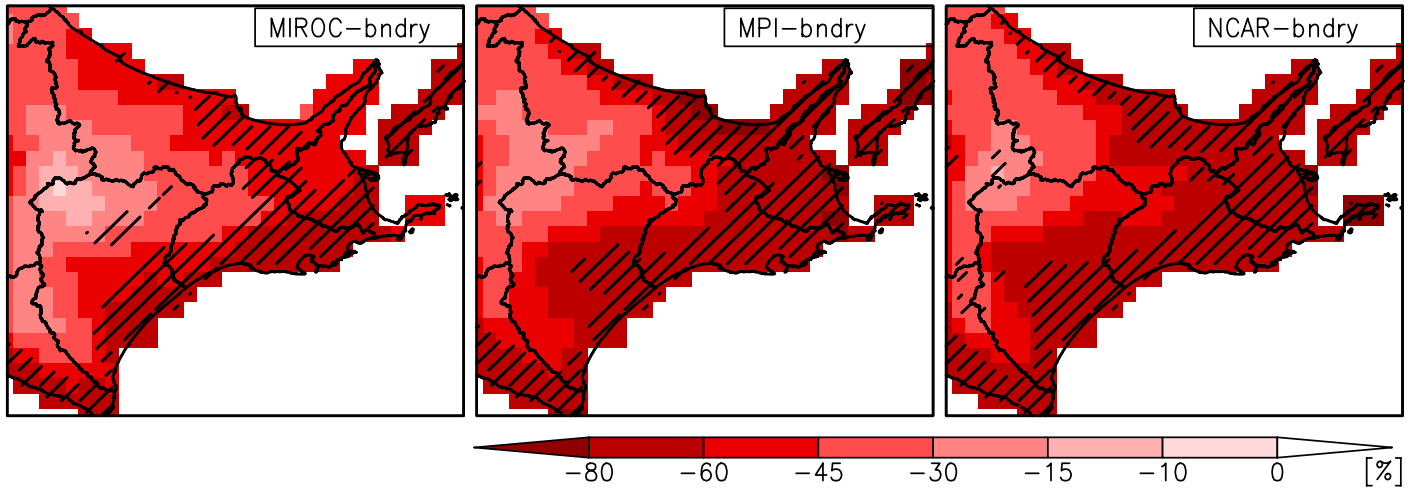

Fig. 2. (a) The increase in December-January-February (DJF) mean surface air temperatures (SATs) by global warming (K) for (left) MIROC-, (centre) MPI-, and (right) NCAR-boundary climate scenarios based on DDS over Hokkaido. The colour reference is as below and the hatches show the areas exceeding a significant level at $10 \%$. (b) The increase rate in DJF precipitation by global warming. (c) The increase rate in DJFmean snow depth by global warming (\%). 
by approximately $2 \mathrm{~K}$ (Inatsu et al. 2015). The DDS data were provided as hourly meteorological data with a single regional model of the Japan Meteorological Agency (Kuno and Inatsu 2014) but we used the daily mean. Based on the data, the SATs averaged over December-January-February (DJF) months increased by $3 \mathrm{~K}$ and a bit more in the Pacific side for the MIROCand MPI-boundary scenarios, and the SATs increased by more than $4 \mathrm{~K}$ for the NCAR-boundary scenario (Fig. 2a). Consistent with the increase in SATs, the DJF-mean snow depth significantly decreased along the coastal regions in all scenarios (Fig. 2c). The snow depth in mountainous regions (Fig. 1) does not change very much, in contrast. We found no significant signals on precipitation except for a part of coastal areas in the MIROC-boundary scenario (Fig. 2b).

Before the analysis, the bias of the DDS data was corrected. We applied a simple way to temperature and precipitation data. The reference monthly climatology was set to the 10-year average of AMeDAS observation data from 1990/1991 to 1999/2000 winters. The simulated monthly climatology was similarly calculated for the MIROC-, MPI-, and NCAR-boundary present-climate scenarios. The bias correction coefficient (BCC) for temperature is defined as the simulated climatology subtracted from the reference and the $\mathrm{BCC}$ for precipitation is the simulated climatology divided into the reference. The BCC is then a function of GCM and month. The daily temperature of the model output was corrected by the addition of $\mathrm{BCC}$, and the daily precipitation was corrected by the multiplication of BCC.

\subsection{Snow-depth model}

A simple snow-depth model was constructed to be fit with the snow depth observation over eastern Hokkaido. The daily snow depth is assumed to follow

$$
\frac{d S}{d t}=-\alpha S-\beta(S) H(T) T+\gamma H(-T) R,
$$

where $S$ is snow depth $(\mathrm{cm}), T$ is SAT $\left({ }^{\circ} \mathrm{C}\right), R$ is rainfall $(\mathrm{mm}$ day $^{-1}$ ), and $H$ is Heaviside hyper-function. The first term of rhs of Eq. (1) means the snow packing with a rate of $2 \%$ /day here. The second term means the melting effects only working above the freezing point with $\beta$ of $1 \mathrm{~cm} /\left({ }^{\circ} \mathrm{C}\right.$ day $)$ for $S>20 \mathrm{~cm}$ and $2 \mathrm{~cm} /\left({ }^{\circ} \mathrm{C}\right.$ day) otherwise. The final term means the snow accumulation by snowfall with the fresh-snow density where $\gamma$ is set to $1 \mathrm{~cm} / 1 \mathrm{~mm}$ (equivalently $0.1 \mathrm{~g} \mathrm{~cm}^{-3}$ ). This simple model neglects the effects of radiation, snow drift due to blizzard, and wet snowfall above the freezing point. The ground is assumed to be flat.

The main purpose to use this model is to estimate plausible timeseries of snow depth from bias-corrected SAT and precipitation. The DDS also provided the snow-depth time-series but because it has a bias, the present-climate simulation did not reproduce the observation well. However, unlike temperature and precipitation, the bias of snow depth has hardly been corrected with formulae such as a simple addition or a simple multiplication because it must keep consistency with the bias-corrected temperature and precipitation. This is the reason why the snowdepth model is inevitable in this study. The snow-depth model was integrated at each AMeDAS site (Fig. 1) for each scenario and each year. The period of an integration is from 1 November to 30 April of the following year. We also perform the parameter-sweep experiments with an aid of the snow model forced by meteorological data modified from the reference AMeDAS observation at Obihiro (Fig. 1). The sweeping parameters are temperature and precipitation: A range from -2 to $6 \mathrm{~K}$ is simply added to daily temperature data and a range from 0.5 to 2.0 is simply multiplied to daily precipitation data.

\subsection{Empirical relation to find soil-frost depth}

An empirical relation between wintertime maximum soil-frost depth $D$ and cumulative freezing degree-days (CFD)

$$
D=\sqrt{\mathrm{CFD}}
$$

is used in this paper. The coefficient $C$ partly depends on the soil property, and we assume that $C=1.8$, based on the observation at a site on volcanic-ash soil (Hirota et al. 2006), mostly prevailed over eastern Hokkaido. The CFD is calculated from daily SAT and snow-depth (Fukuda 1982; Tsuchiya 1985) as

$$
\mathrm{CFD}=\int_{\Omega}-T(t) H(-T) H(20-S(t)) d t,
$$

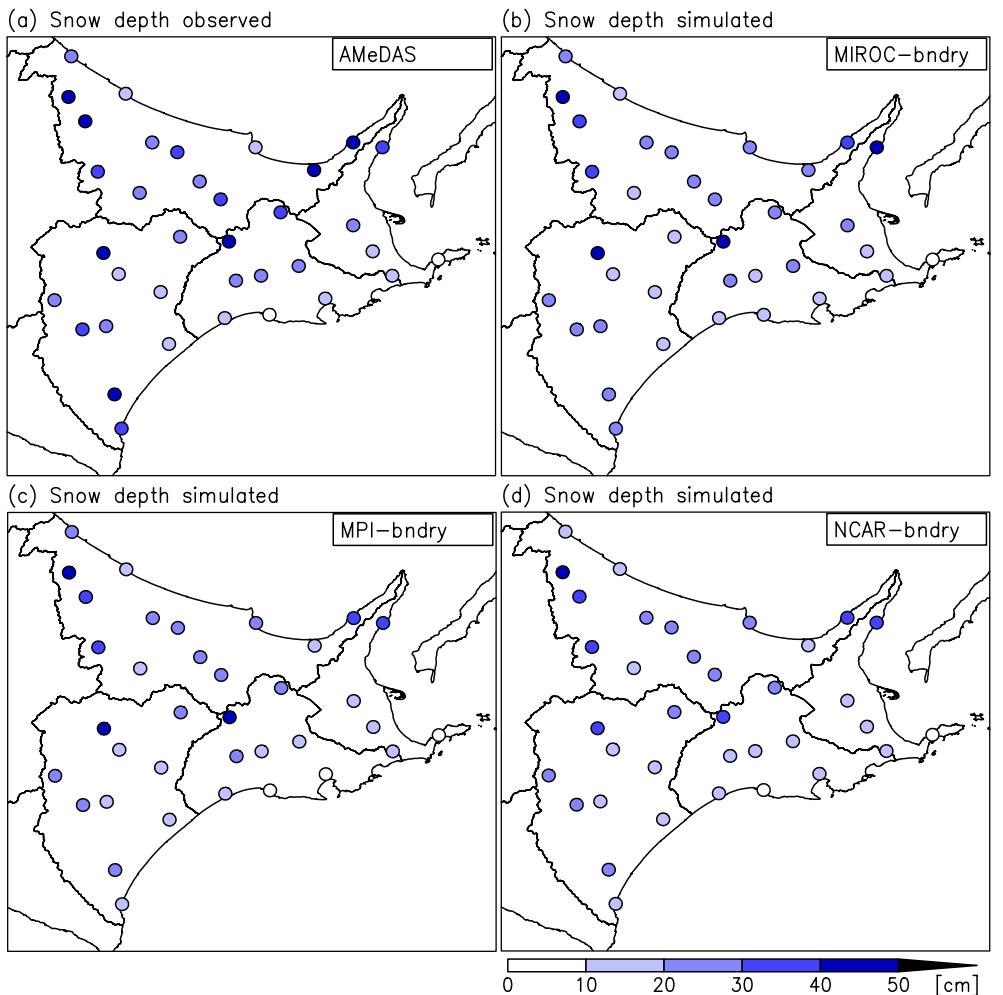

Fig. 3. (a) The DJF-mean snow depth $(\mathrm{cm})$ observed at the AMeDAS sites during 1990/91 to 1999/2000. The colour reference is below (d). (b-d) The DJF-mean snow depth simulated with a simple snow-depth model forced by bias-corrected SAT and precipitation data of (b) MIROC-, (c) MPI-, and (d) NCAR-boundary present-climate scenarios. 
where $\Omega$ is the period from 1 November to 28 February of the following year and the other notations are same as Eq. (1).

\section{Results}

We first validate the snow-depth model by evaluating of the snow depth at Obihiro (Fig. 1) based on the AMeDAS observation for a case with snowcover only in late winter and another case with snowcover throughout the winter. As an example for the former case of 1994/1995 winter (Fig. 4a), the snow depth was about $10 \mathrm{~cm}$ till the mid-January and then it suddenly increased up to $80 \mathrm{~cm}$ at the peak. The simulation perfectly followed the observation, except for a slight underestimation found in the peak and in a gradual decline after that. The other case is 1998/1999 winter, in which the snow depth ranged from 20 to $60 \mathrm{~cm}$ throughout the DJF months (Fig. 4b). The snow simulation almost reproduced the snow depth in the season with a bit underestimation after January. We have already checked the model availability in another site with a warmer climate than Obihiro (not shown), so that the snow model would be expectedly reliable under the global warming environment. The DJF-mean snow depth in the snow simulation based on the bias-corrected DDS data for the present-climate scenarios (Figs. 3b, c, and d) is almost comparable to the observed one (Fig. 3a). The root-mean-square error of the snow depth for all stations is about $8 \mathrm{~cm}$, almost half of that given with the DDS (not shown)

Figures $5 \mathrm{a}, 5 \mathrm{~b}$, and $5 \mathrm{c}$ show the statistically-estimated maximum soil-frost depth difference between 10-year averarge result under $+2-\mathrm{K}$ world scenario and that under present-climate scenario. A significant decrease in soil-frost depth is found in most of the coastal sites. Especially more than $10 \mathrm{~cm}$ shallowing is likely in the sites along the Pacific with $<20 \mathrm{~cm}$ snow depth under the present climate (Figs. 3b, c, and d). We also find a significant signal at several points in central Tokachi subprefecture particularly for MIROC- and NCAR-boundary scenarios, in which the difference between present and future is larger than the interannual variability (Fig. 5d). In contrast, other inland regions miss a significant signal, which may be attributed to a counteracting response to global warming: the soil thawing is promoted in a less snowy condition, while the soil freezing is possibly induced by removing the insulation effect in a snowy condition.

The parameter-sweep experiment with the reference observation at Obihiro helps us to interpret the above results. In
$1994 / 1995$ winter as a less snowy case, the SAT is below the freezing point through the DJF months (Fig. 4a). The soil-frost depth is about $31 \mathrm{~cm}$ in the hindcast estimation plotted at the origin of Fig. 4c. At the reference precipitation, we found a gradual decrease in soil-frost depth as the SAT increase. If the SAT increased by $3 \mathrm{~K}$ as the climate scenario that we gave, the soilfrost depth would decrease from 31 to $24 \mathrm{~cm}$. The soil-frost depth is utterly insensitive to the precipitation changes, however, as the snow depth would not attain $20 \mathrm{~cm}$ in early winter if precipitation doubled because the snow depth is nearly zero at the reference; it is noted, if precipitation were added by $100 \mathrm{~mm} / \mathrm{month}$ in December, the result would be like the counterpart experiment (Fig. 4d). The low sensitivity to precipitation would not change in a warmer climate. Since this case shows a typical winter in the coastal region, this parameter-sweep experiment explains the soil-frost change there (Fig. 5): global warming would prevent soil freezing in the region with DJF-mean snow depth less than $20 \mathrm{~cm}$ under the present climate, because the insulation effect does not much work at present.

In 1998/1999 winter (Fig. 4b), in contrast, the SAT is below the freezing point but the thick snow is covered through the season. The empirically estimated soil-frost depth is only $10 \mathrm{~cm}$ in the hindcast estimation (Fig. 4d). At the reference precipitation, the soil-frost depth increases as the SAT. For example, it would change from $10 \mathrm{~cm}$ to $25 \mathrm{~cm}$ in the SAT increase by $3 \mathrm{~K}$. Contrary to a less snowy case, this response is caused by the soil freezing for snow depth decrease in early winter. Moreover at the reference SAT, the soil-frost depth rapidly increases as the precipitation decreases. If the precipitation decreased by half, the soil-frost depth would be fourfold. Different from the less-snowy case (Fig. $4 \mathrm{c}$ ), the soil-frost depth would be sensitive to precipitation as long as the temperature increase is less than $4 \mathrm{~K}$; otherwise it would be insensitive because the snow depth cannot attain $20 \mathrm{~cm}$ due to the domination of rainfall under a high temperature environment. Moderate global warming would thus encourage the soil freezing in the snowy season, because the insulation effect would be weakened. This was argued as the paradox of cooling winter soil temperatures in a warmer atmosphere (Brown and DeGaetano 2011). In the land sites of eastern Hokkaido, the soil-frost might not change in response to global warming (Fig. 5), because some years are less snowy like 1994/1995 but other years are snowy like 1998/1999. (a) Snow depth and daily temperature (1994/1995)

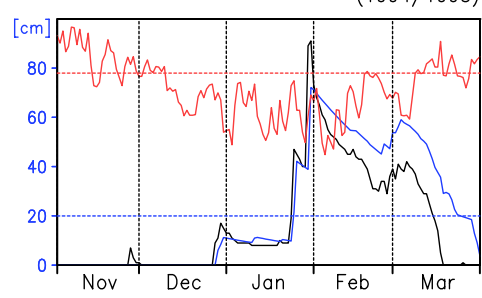

(c) Maximum soil-frost depth distribution

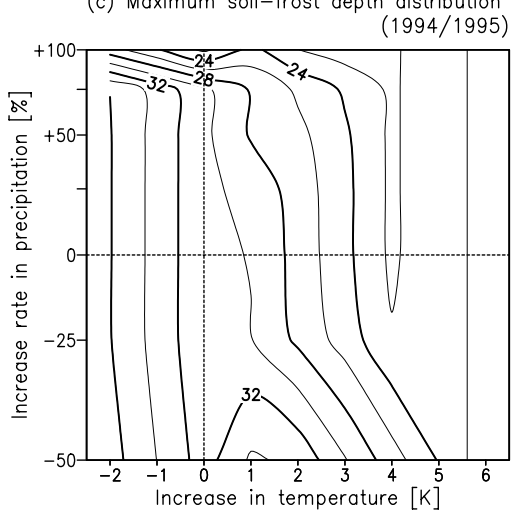

(b) Snow depth and daily temperature

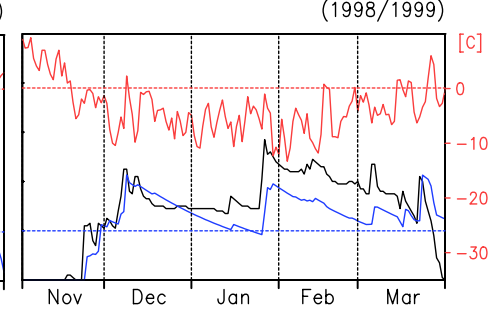

(d) Maximum soil-frost depth distribution (1998/1999)

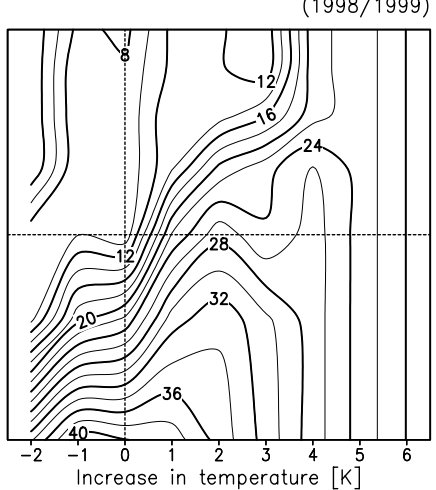

Fig. 4. (Upper panels) The observed time-series of (black) snow depth (cm; the leftmost label) and (red) SAT $\left({ }^{\circ} \mathrm{C}\right.$; the rightmost label) from 1 November to 31 March of the following year for (a) 1994/1995 and (b) 1998/1999 winters. The blue line denotes the snow depth simulated by the snow model. The blue and red dotted lines indicate the snow depth at $20 \mathrm{~cm}$ and the SAT at the freezing point, respectively. (Lower panels) The statisticallyestimated maximum soil-frost depth distribution in space spanned by the increase in SATs $(\mathrm{K})$ and the increase rate in precipitaion (\%) modified from the reference AMeDAS data observed at Obihiro for (c) 1994/1995 and (d) 1998/1999 winters. Contour interval is $2 \mathrm{~cm}$. The dotted lines indicate the reference SAT and precipitation. 
(a) Maximum soil-frost depth (future-present) (b) Maximum soil-frost depth (future-present)
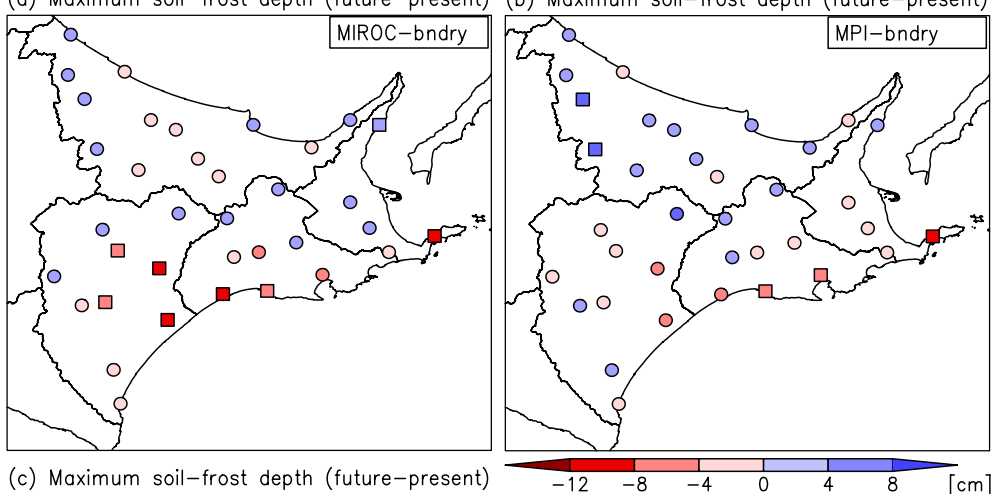

(c) Maximum soil-frost depth (future-present)
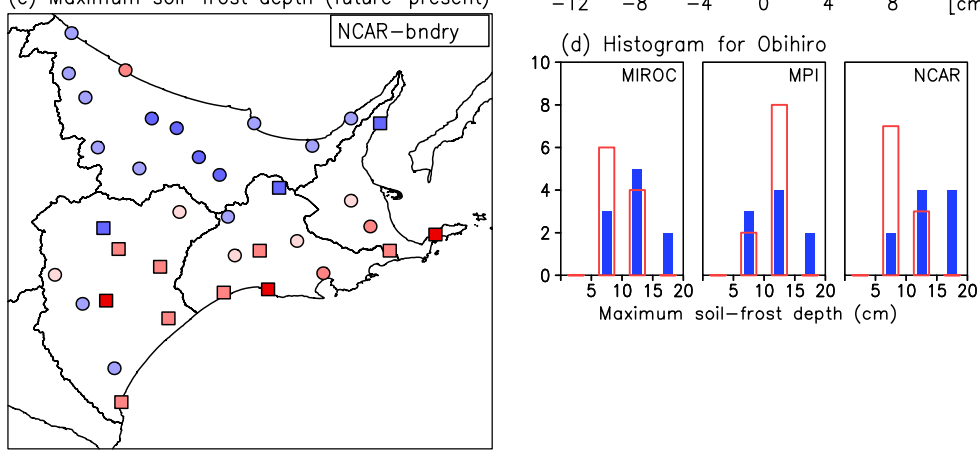

Fig. 5. The increase in wintertime maximum soil-frost depth $(\mathrm{cm})$ in response to global warming for (a) MIROC-, (b) MPIand (c) NCAR-boundary climate scenarios. The 10-year average of future-climate value subtracted from that of present-climate value is shown on the map. The colour reference is below (b). Sites exceeding a significance level at $10 \%$ are marked by square. (d) The number of years for wintertime maximum soilfrost depth at Obihiro for three scenarios. The blue closed and red open bins denote the present-climate and the future-climate results, respectively.

\section{Conclusion and discussion}

We have examined an impact of global warming to the soilfrost depth in eastern Hokkaido. The bias-corrected DDS data with an aid of the snow model were applied to the empirical relation between the soil-frost depth and the CFD in the condition of $<20 \mathrm{~cm}$ snow depth. Consequently the soil-frost depth significantly decreased in the coastal regions and in central Tokachi subprefecture, while the soil-frost depth was likely kept in most of the inland sites. Parameter-sweep experiments for two observed cases explained that global warming would bring the soil warming in the environment where the insulation effect does not work at present, like the coastal regions of eastern Hokkaido. In contrast, the soil-frost depth tended to increase in a snowy case by global warming, because the insulation effect would likely be eliminated in the future. The parameter-sweep experiments performed in this study thus clearly contrasted the augmentation of the melting effect in a less snowy case with the declination of the insulation effect in a snowy case in response to global warming.

Our interpretation can be applied to the case for a recent tendency in early-winter snowfall events and its subsequent decreace in soil-frost depth (Hirota et al. 2006; Yazaki et al. 2013a). The soil-frost depth was much sensitive to early-winter snowfall under the present climate, which was demonstrated in the difference between the two typical cases. The increase in early-winter snowfall events shifts the regime from Fig. $4 \mathrm{c}$ to $4 \mathrm{~d}$. Therefore, the key point is how the occurrence probability of the events changes by global warming. The composited synoptic chart (Fig. 6) tells that heavy snowfall events at Obihiro are mainly caused by the extratropical cyclone passages in the south of the site. The multimodel analysis (Chang et al. 2012) revealed that the storm-track activity would be enhanced especially in northern Japan (Inatsu and Kimoto 2005) due to the northward shift of the jet stream (Mizuta 2012). This is suggestive of the possibility that heavy snow events would increase in winter, though DJF precipitation would not change significantly (Fig. 2b).

Our finding is related to agrometeorological technology recently disseminated in central Tokachi subprefecture: a few sites there indicated a significant decrease of soil-frost depth even though it is model dependent. The soil-frost with a sufficient depth as in 1994/1995 case (Figs. 4a and 4c) kills small potato tubers

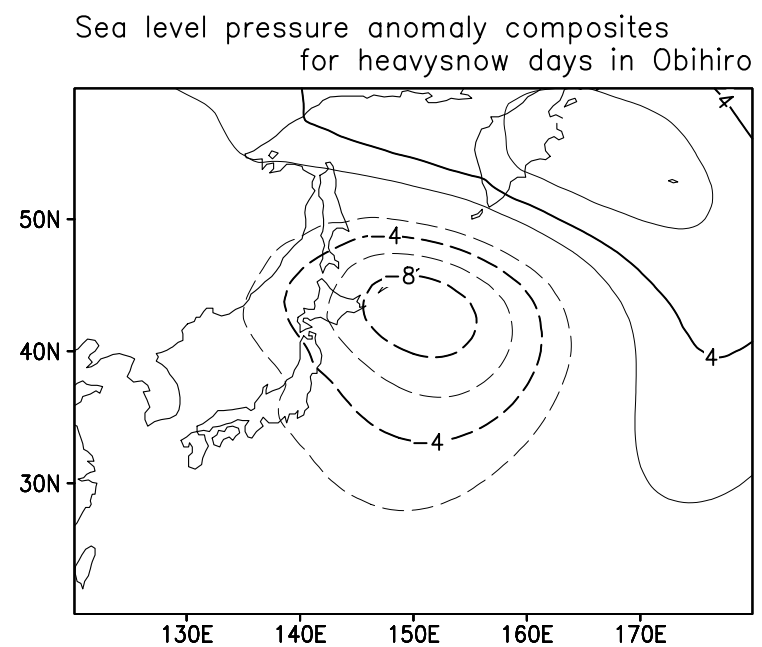

Fig. 6. Mean sea-level pressure anomaly composites for days when daily snowfall exceeded $10 \mathrm{~cm}$ at Obihiro in November-to-March months during $1960 / 61$ to $2014 / 15$. The contour interval is $2 \mathrm{hPa}$ with negative contours dashed and zero contour omitted.

that were unintentionally left over the field when harvesting, but the unfrosted condition with an early-winter heavy-snow event as in 1998/1999 case (Figs. 4b and 4d) lets them survive over winter and sprout in spring, causing the interference with the growth of another crop in rotation fields or the infestation of endemic diseases. Recently the snow plowing by machine operators has been attempted to promote the soil frosting (Hirota et al. 2012). As the snow plowing corresponds to the decrease in precipitation under the thick-snow covering regime, a sucessful control makes the situation go downward from the reference in Fig. 4d. On the other hand, global warming would basically eliminate the insulation effect as already discussed. The precipitation would not change siginificantly in the future (Fig. 2b), but, even though it increased by $50 \%$ in the $+3-\mathrm{K}$ temperature environment, the soil-frost depth would slightly increase (Fig. 4d). This result seems consistent with Hirota et al. (2011), who suggested that this soil-frost control 
technology could be utilised under a $+3-\mathrm{K}$ scenario.

Finally, we shortly comment the limitation of the study, which mainly stems from the use of the empirical relation (Eq. 2). First, the coefficient of Eq. (2) is different site by site. The result summarised above is however robust, because it does not qualitatively depend on the coefficient. Moreover, despite large interannual variability, the empirical relation can be available over eastern Hokkaido for any winters. This means that the relation must be available in the range of the parameter field that we swept in Figs. $4 \mathrm{c}$ and $4 \mathrm{~d}$.

\section{Acknowledgments.}

We would like to thank Drs. T. Sato, T. J. Yamada, H. Tanaka, Y. N. Sasaki, and Prof. S. Minobe for valuable comments for our study. MI is supported by Social Implementation Project for Climate Change Adaptation Technology of Ministry of Education, Culture, Sports, Science, and Technology (MEXT) of Japan. TH is supported by Grants-in-Aid for Scientific Research 25292153 and $15 \mathrm{~K} 14831$ of MEXT.

Edited by: T. Yamazaki

\section{References}

Brown, P. J., and A. T. DeGaetano, 2011: A paradox of cooling winter soil surface temperatures in a warming northeastern United States. Agri. Forest Meteor., 151, 947-956.

Campbell, J. L., S. V. Ollinger, G. N. Flerchinger, H. Wicklein, K. Hayboe, and A. S. Bailey, 2010: Pasr and projected future changes in snowpack and soil frost at the Hubband Book Experiment Forest, New Hampshire, USA. Hydrol. Process, 24, $2465-2480$.

Chang, E. K. M., Y. Guo, and X. Xia, 2012: CMIP5 multimodel ensemble projection of storm track change under global warming. J. Geophys. Res., 117, D23118.

Collins, W. D., C. M. Bitz, M. L. Blackmon, G. B. Bonan, C. S. Bretherton, J. A. Carton, P. Chang, S. C. Doney, J. J. Hack, T. B. Henderson, J. T. Kiehl, W. G. Large, D. S. McKenna, B. D. Santer, and R. D. Smith, 2006: The community climate system model version 3 (CCSM3). J. Climate, 19, 2122-2143.

Fukuda, M., 1982: The Estimation method of frost penetration depth under snow packs condition. Research reports of grant-in-aid for special project of Hokkaido university in study on snow distribution and characteristics and its effect on frozen soil depth, vegetation and insect ecology in Hokkaido 55-74 (in Japanese).

Grundstein, A., P. Todhunter, and T. Mote, 2005: Snowpack control over the thermal offset of air and soil temperatures in eastern North Dakota. Geophys. Res. Lett., 32, L08503.

Hasumi, H., and S. Emori, Eds., 2004: K-1 coupled GCM (MIROC) description. K-1 Technical Report 1, CCSR, University of Tokyo, Tokyo.

Hirota, T., Y. Iwata, M. Hayashi, S. Suzuki, T. Hamasaki, R. Sameshima, and I. Takayabu, 2006: Decreasing soil-frost depth and its relation to climate change in Tokachi, Hokkaido, Japan. $J$. Meteor. Soc. Japan, 84, 821-833.

Hirota, T., K. Usuki, M. Hayashi, M. Nemoto, Y. Iwata, Y. Yanai, T. Yazaki, and S. Inoue, 2011: Soil frost control: agricultural adaptation to climate variability in a cold region of Japan. Mitig. Adapt. Strat. Global Change, 16, 791-802.

Hirota, T., T. Yazaki, K. Usuki, M. Hayashi, M. Nemoto, Y. Iwata, Y. Yanai, S. Inoue, M. Shirahata, T. Kajiyama, K. Araki, and K. Maezuka, 2012: Soil frost control: its application to volunteer potato management in a cold region. Plant and Microbe Adaptation to Cold in a Changing World. R. Imai, M. Yoshida, and N. Matsumoto, Eds., Springer, 51-62.

Imai, R., M. Yoshida, and N. Matsumoto, 2013: Plant and Microbe Adaptations to Cold in a Changing World, Springer, $352 \mathrm{pp}$.

Inatsu, M., and M. Kimoto, 2005: Two types of interannual variability of the mid-winter storm-tracks and their relationship to global warming. SOLA, 1, 61-64.

Inatsu, M., T. Sato, T. J. Yamada, R. Kuno, S. Sugimoto, M. A. Farukh, Y. N. Pokhrel, and S. Kure, 2015: Multi-GCM by multi-
RAM experiments for dynamical downscaling on summertime climate change in Hokkaido. Atmos. Sci. Lett., 16, 297-304.

Intergovernmental Panel on Climate Change, 2007: Climate change 2007: The physical science basis. Contribution of Working Group I to the Fourth Assessment Report of the IPCC, S. Solomon et al., Eds., Cambridge Univ. Press, Cambridge, United Kingdom, 996 pp.

Intergovernmental Panel on Climate Change, 2013: Climate Change 2013: The Physical Science Basis. Contribution of Working Group I to the Fifth Assessment Report of the Intergovernmental Panel on Climate Change, T. Stocker, D. Qin, G.-K. Plattner, M. Tignor, S. Allen, J. Boschung, A. Nauels, Y. Xia, V. Bex, and P. Midgley, Eds., Cambridge University Press, Cambridge, United Kingdom.

Iwata, Y., M. Hayashi, S. Suzuki, T. Hirota, and S. Hasegawa, 2010: Effects of snowcover on soil freezing, water movement and snowmelt infiltration. Water Resour. Res., 46, W09504.

Jacobs, A. F. G., B. G. Heusinkveld, and A. A. M. Holtslag, 2011: Long-term record and analysis of soil temperatures and soil heat fluxes in a grassland area, the Neatherland. Agri. Forest Meteor. 151, 794-780.

Kobayashi, S., Y. Ota, Y. Harada, A. Ebita, M. Moriya, H. Onoda, K. Onogi, H. Kamahori, C. Kobayashi, H. Endo, K. Miyaoka, and K. Takahashi, 2015: The JRA-55 reanalysis: General specifications and basic characteristics. J. Meteor. Soc. Japan, 93, 5-48.

Kuno, R., and M. Inatsu, 2014: Development of sampling downscaling: A case for wintertime precipitation in Hokkaido. Climate Dyn., 43, 375-387.

Maurer, E. P., L. Brekke, T. Pruitt, and P. B. Duffy, 2007: Fineresolution climate projections enhance regional climate change impact studies. Eos Trans. AGU, 88, 504.

Mizuta, R., 2012: Intensification of extratropical cyclones associated with the polar jet change in the CMIP5 global warming projections. Geophys. Res. Lett., 39, L19707.

Reinsdorf, E., and H.-J. Koch, 2013: Modeling crown temperature of winter sugar beet and its application in risk assessment for frost killing in Central Europe. Agri. Forest Meteor., 182-183, 21-30.

Roeckner, E., G. Bäuml, L. Bonaventura, R. Brokopf, M. Esch, M. Giorgetta, S. Hagemann, I. Kirchner, L. Kornblueh, E. Manzini, A. Rhodin, U. Schlese, U. Schulzweida, and A. Tompkins, 2003: Part I: Model description, The atmospheric general circulation model ECHAM5, MPI Meteor. Rep. 349, MPI for Meteorol, Hamburg.

Shimoda, S., T. Yazaki, Z. Nihio, T, Hamasaki, and T. Hirota, 2015: Possible soil frost control by snow compaction on winter wheat fields. J. Agri. Meteor, 71, 276-281.

Sinha, T., and K. A. Cherkauer, 2010: Impacts of future climate change on soil frost in the midwestern United States. J. Geophys. Res., 115, D08105.

Tsuchiya, F., 1985: Effect of soil frost and frost penetration on volcanic ash soil in agricultural field in Tokachi, eastern Hokkaido, Japan. Ph.D. thesis, Hokkaido University, Japan, 234 pp. (in Japanese).

Wood, A. W., L. R. Leung, V. Sridhar, and D. P. Lettemaier, 2004: Hydrologic implications of dynamical and statistical approaches to downscaling climate model outputs. Climate Change, 62, 189-216.

Yazaki, Y., T. Hirota, Y. Iwata, S. Inoue, K. Usuki, T. Suzuki, M. Shirahata, A. Iwasaki, T. Kajiyama, K. Araki, Y. Takamiya, and K. Maezuka, 2013a: Effective killing of volunteer potato (Solanum tuberosum L.) tubers by soil frost control using agrometeorological information -An adaptive countermeasure to climate change in a cold region. Agri. Forest Meteor., 182-183, 91-100.

Yazaki, T., Y. Iwata, T. Hirota, Y. Kominami, T. Kawakata, T. Yoshida, Y. Yanai, and S. Inoue, 2013b: Influences of winter climatic conditions on the relation between annual mean soil and air temperatures from central to northern Japan. Cold Reg. Sci. Tech., 85, 217-224.

Zhang, Y., C. Wenjun, S. L. Smith, D. W. Riseborough, and J. Cihlar, 2005: Soil temperature in Canada during the twentieth century: Complex responses to atmospheric climate change. J. Geophys. Res., 110, D03112.

Manuscript received 26 March 2016, accepted 9 June 2016

SOLA: https://www.jstage.jst.go.jp/browse/sola/ 